\title{
Über die Zusammenziehung der Arterienwand des Kaninchens nach dem Tode.
}

\author{
家鬼の動脉壁の死後收縮について. \\ Mitsugu TANAKA 田中 貢.
}

(Eingegangen am 23. Februar 1958.)

Bei der Leiche sind die Arterien, mehr oder weniger stark zusammengezogen, dadurch, da $\beta$ das in ihnen enthaltene Blut nach den Venen ausgetrieben ist. Der Grad der Zusammenziehung läßt sich aus der Stärke der an der Innenfläche der Gefäßwand entstandenen Falten erschließen. Ich untersuchte an verschiedenen Arterien des getöteten Kaninchens die Verhältnisse zw ischen der Faltungsstärke der Intima und der Menge der Muskel- und elastischen Elemente in der Arterienwand, worüber unten berichtet werden soll.

\section{Material und Methode.}

Ein gesundes männliches Kaninchen von $2.3 \mathrm{~kg}$ wurde durch Verblutung aus der Halsarterie getötet. Man bewahrte die Leiche 6 Stunden lang im Eisschrank auf und entnahm kleine Stücke von 13 Arterien mit dem sie umgebenden Gewebe und zwar von Arcus aortae, Aorta thoracica und abdominalis, A. carotis communis, intercostalis, subclavia, thoracica interna, mesenterica superior, coronalis sinistra, cerebralis anterior, renalis, brachialis und poplitea. Sie wurden dann alle gleichzeitig in 10\%igem Formalin fixiert, unter derselben Bedingung entwässert, in Paraffin eingebettet und genau $10 \%$ dick quergeschnitten. Wie bei meiner früheren Arbeit (1956) wurde die Innenfläche der Intima in 300facher Vergrößerung abgezeichnet. Bei jeder Arterie wurden die Falten in dem Abstand von $250 \mu$ zwischen 2 Punkten beobachtet. Das Verhältnis dieses Abstandes zu der Länge der Faltenoberfläche wurde als der Zusammenziehungsindex der Innenfläche der Arterie angenommen.

Das Verhältnis des Flächenanteils der ganzen Muskulatur oder elastischen Fasern in der Querschnittsfläche der Media zu dem ganzen Flächeninhalt derselben ließ sich mit Prozentsatz ausdrücken. Die Resultate sind in der folgenden Tabelle und Abb. 1 angegeben. Die Querschnitte wurden dabei zur Untersuchung der Muskulatur nach der Azanmethode und zu der der elastischen Elemente mit Resorcinfuchsin gefärbt und wurde nach YAMADA u. a. (1957) in einer gewissen Vergrößerung photographiert. Auf das Bild legte man ein Batt Papier, bestrich darauf mit schwarzer Tinte nur den Flächenanteil der Muskel- bzw. elastichen Elemente, wobei man das Ganze von unten beleuchtete und das Verhältnis dieses bestrichenen Anteils zu der ganzen Fläche der Media im Prozentsatz bestimmte. Dazu hatte man zuvor Standardpapiere von 10 Dunkelabstufungen von 10- bis 100\%iger Dunkelheit herge- 
Der Zusammenziehungsindex der Innenfläche der Arterien, die Dicke der Intima und Media und die Menge der Muskel- und elastischen Elemente in der Media.

\begin{tabular}{l|c|c|c|c|c}
\hline & $\begin{array}{c}\text { Zusammenzie- } \\
\text { hungsindex d. } \\
\text { Innenfläche d. } \\
\text { Arterienwand } \\
(\%)\end{array}$ & $\begin{array}{c}\text { Dicke } \\
\text { d. } \\
\text { Intima } \\
(\mu)\end{array}$ & $\begin{array}{c}\text { Dicke } \\
\text { d. } \\
\text { Media } \\
(\mu)\end{array}$ & $\begin{array}{c}\text { Menge d. } \\
\text { Muskelelemente } \\
\text { in d. Media } \\
(\%)\end{array}$ & $\begin{array}{c}\text { Menge der } \\
\text { elastischen } \\
\text { Elemente in } \\
\text { d. Media } \\
(\%)\end{array}$ \\
\hline Arcus aortae & 8.6 & 23 & 365 & 10 & 60 \\
Aorta thoracica & 17.6 & 16 & 205 & 12 & 47 \\
Aorta abdom. & 19.4 & 13 & 214 & 20 & 36 \\
A. carot. comm. & 21.1 & 12 & 210 & 23 & 24 \\
A. intercost. & 21.9 & 2 & 14 & 25 & 23 \\
A. subclav. & 30.6 & 9 & 84 & 30 & 30 \\
A. thorac. int. & 34.8 & 3 & 35 & 34 & 36 \\
A. mesent. cran. & 34.8 & 14 & 168 & 34 & 14 \\
A. coron. cord. $\sin$. & 35.4 & 2 & 40 & 39 & $\mathbf{1 0}$ \\
A. cerebr. ant. & 35.9 & 3 & 20 & 40 & 16 \\
A. renalis & 43.2 & 7 & 160 & 41 & 18 \\
A. brachialis & 58.4 & 5 & 146 & 47 & 12 \\
A. poplitea & 73.3 & 5 & 158 & 54 &
\end{tabular}

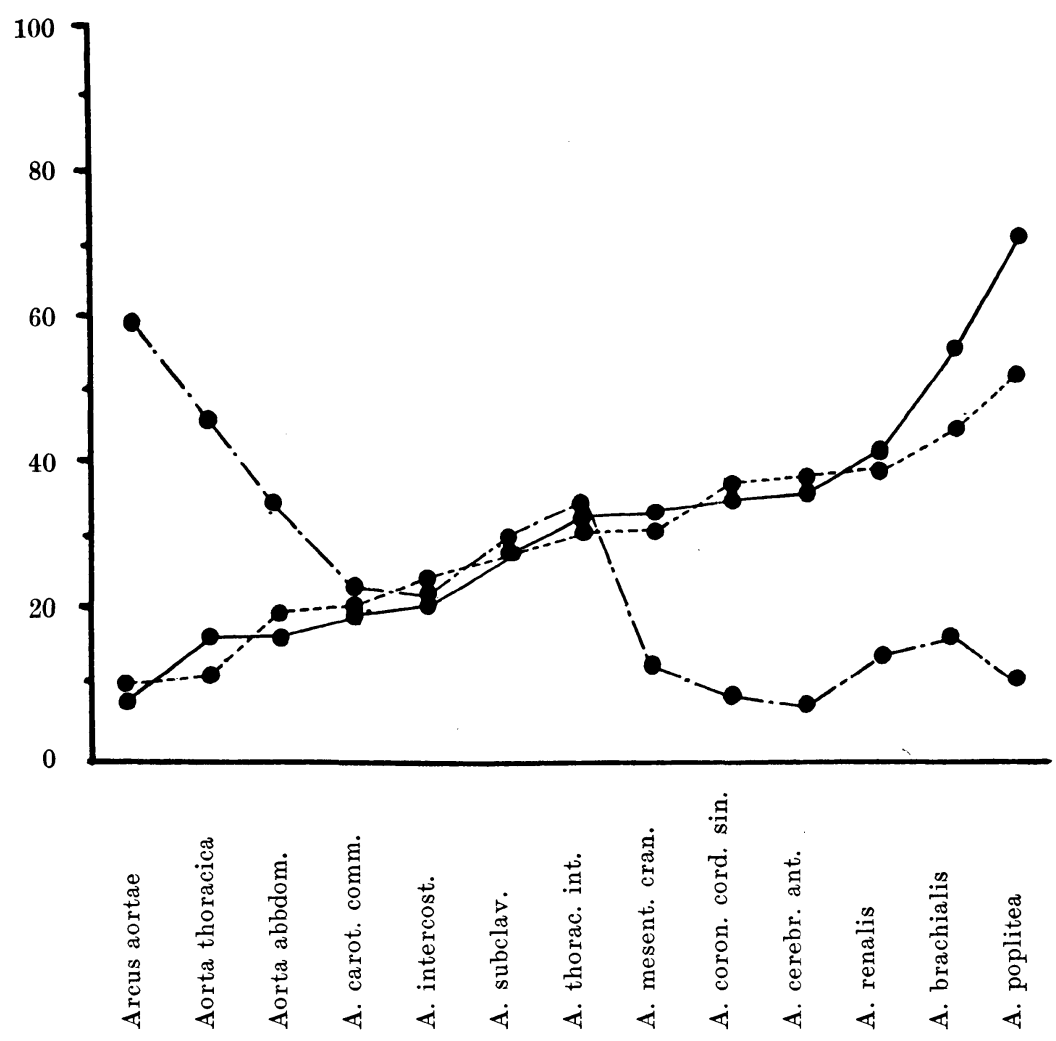

Abb. 1. Der Zusammenziehungsindex der Innenfläche der Arterienwand in den Querschnitten und die Menge der Muskel- und elastischen Elemente in der Media (\%). Zusammenziehung der Innenfläche, .......... Menge der Muskelele. mente in der Media, _- Menge der elastischen Elemente in der Media. 
stellt, indem man auf einem Papier von derselben Beschaffenheit schwarze Tinte verschieden stark strich, und hatte die Dunkelheit dieser Standardpapiere genau mit dem elektrischen Photometer bestimmt. Die in der gleicher Weise genau bestimmte Dunkelheit des oben erwähnten bestrichenen Papieres wurde mit der Dunkelheit der Standardpapiere verglichen und dadurch wurde das Verhältnis der Muskel- bzw. elastischen Ellemente zur ganzen Fläche der Media im Prozentsatz ermittelt.

\section{Ergebnisse.}

Die im Querschnitt der Arterien beobachteten Falten der Innenenfläche der Gefäßwand sind, wie in Abb. 2 dargestellt ist, bei den Arterien von elastischem

Arcus aortae

Aorta thoracica

Aorta abdom.

A. carot. comm.

A. intercost.

A. subclav.
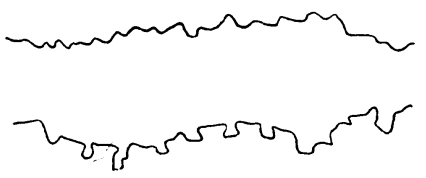

A. thorac. int.

A. mesent. cran

A. coron. cord. sin.

A. cerebr. ant.
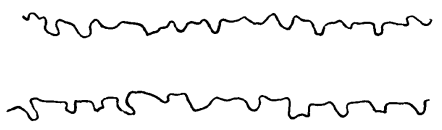$$
\text { (5) }
$$
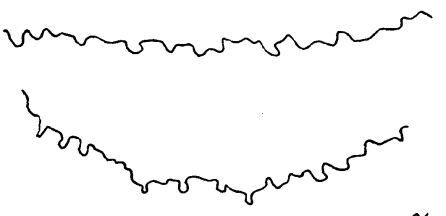

A. renalis

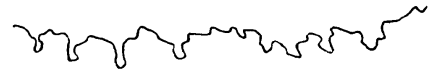

A. brachialis

A. poplitea

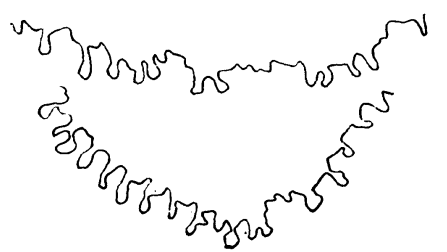

Abb. 2. Die Falten an der Innenfläche in den Querschnitten der Arterien. $180 \times$ 
Typus in der Nähe des Herzens von kleiner Höhe und Zahl, dagegen sind sie höher und zahlreicher bei denen von muskulösem Typus in der Peripherie. Sie sind unter dem untersuchten Arterien bei der A. poplitea und brachialis am höchsten und zahlreichsten.

Der Zusammenziehungsindex der Innenfläche der Arterie erweist sich als größer in der umgekehrten Richtung der Reihenfolge der in der Tabelle 1 angegebenen Arteriennamen. Besonders ist der Index bei der A. poplitea am größten und beträgt 73.3\%, dagegen ist dieser beim Arcus aortae am kleinsten und beträgt nur 8.6\%. Allgemein kann man sagen, daß der Zusammenziehungsindex bei den Arterien mit größerer Wanddicke und dickerer Intima und Media kleiner ist.

Die Muskelelemente in der Media sind in umgekehrter Reihenfolge reichlich vorhanden wie bei den in der Tabelle 1 und Abb. 2 angegebenen Arteriennamen. Sie sind vor allem im Arcus aortae arm und nur um 10\% im Verhältnis zu der ganzen Media vorhanden, in den Arterien in der Peripherie aber reich und besonders in der A. poplitea um 54\%. Also ist der Zusammenziehungsindex der Innenfläche der Arterie um so kleiner, je kleiner die Menge der Muskulatur in der Media ist, uud umgekehrt.

Die Menge der elastischen Elemente in der Media ist dagegen je größer in der Reihenfolge der in der Tabelle 1 angegebenen Arteriennamen. Sie sind insbesondere im Arcus aortae reichlich, und zwar die Menge beträgt um 60\% zu der genzen Media. Der Zusammenziehungsindex der Innenf läche ist kleiner bei den Arterien, die die elastischen Elementen reichlicher führen.

\section{Zusammenfassung.}

Die Elastizität der Arterien von elastischem Typus gleicht effektiverweise die Veränderungen des Innendruckes bei der Pulsation aus, die Arterien von muskulösem Typus aber regulieren die Blutverteilung im Körper. Es ist zu vermuten, daß die Arterien von muskulösem Typus sich bei der tödlichen Blutung stark zusammenziehen. Es wurden an den Querschnitten von 13 verschiedenen Arterien aus einem durch Verblutung getöten Kaninchen das Verhältnis zwischen der mit dem Photometer ermittelten Mengen der Muskel- und elastischen Elemente in der Media und der Stärke der an der Innenfläche der Arterienwand entstandenen Faltungen beobachtet. Es ließ sich feststellen, daß der Zusammenziehungsindex sich bei den mittelgroßen, an Muskulatur reichen Arterien, vor allem bei der A. poplitea und brachialis, als groß erweist, dagegen ist dieser bei den muskelarmen Arterien von elastischem Typus, besonders beim Arcus aortae, kein.

\section{内 容自抄.}

脱血で殺された家鬼の13種の動脉の光度計で測られた中膜の筋と弾性成分の量 と脉壁の内面にできる皺璧の強さの関係が調ベられた。 中等の太さの筋飞富む動 脉, 特飞膝窩動脉と上腕動脉では收縮率が大で, 筋の少い弾性型, 特飞大動脉弓 ではそれが小であることが示された。 


\section{Literatur.}

Tanaka, M.: Vergleichende Beobachtung der Struktur der Arteria epigastrica cranialis und caudalis des Menschen. Arch. hist. jap. 11 (1956). - Yamada, H., H. Tujita, M. Kano, K. Komuro a. M. Kodama : On the measurement method for the quantitative analysis of tissue components by the electric photometer. (Jap. m. engl. Z-fass.) Arch. hist. anat. jap. 14 (1958). 